\title{
Comment to the letter by Dr. S. Matsubara
}

\author{
Akihiro Hamuro $^{1} \cdot$ Daisuke Tachibana $^{1}$
}

Published online: 17 November 2015

(c) Springer-Verlag Berlin Heidelberg 2015

\section{Dear Editor,}

We thank Dr. Matsubara for the questions and comments.

First, as Dr. Matsubara mentioned [1], massive bleeding from anterior lower uterine segment was controllable by the combination of figure-of-eight suture and Cho's suture in all of our cases $[2,3]$. One reason for high success rate might be the exclusion of placenta increate. Second, bleeding by the tear of the suture of myometrium was also controllable by the additional figure-of-eight suture around the tear and this technique was not difficult in our experience. Of course, assistant needs to show the bleeding points precisely in this situation. Third, we have never needed to use additional treatments including intrauterine balloon after the application of our technique, as we described in the letter. Although we are fully aware of the usefulness of applying balloon in some cases, it should be discussed in another paper.

\section{Compliance with ethical standards}

Conflict of interest The authors declare no potential conflicts of interest with respect to the research, authorship and/or publication of this article.

\section{References}

1. Matsubara S (2015) On-site hemostatic suturing for placenta previa: concerns and clarifications. Arch Gynecol Obstet. doi:10. 1007/s00404-015-3959-8

2. Hamuro A, Tachibana D, Wada N, Kurihara Y, Katayama H, Misugi T, Sumi T, Koyama M (2015) On-site hemostatic suturing technique for uterine bleeding from placenta previa and subsequent pregnancy. Arch Gynecol Obstet 292:1181-1182

3. Cho JH, Jun HS, Lee CN (2000) Hemostatic suturing technique for uterine bleeding during cesarean delivery. Obstet Gynecol 96:129-131

This reply refers to the comment available at doi:10.1007/s00404-015-3959-8.

Daisuke Tachibana

dtachibana@med.osaka-cu.ac.jp

1 Department of Obstetrics and Gynecology, Osaka City

University Graduate School of Medicine, 1-4-3 Asahimachi,

Abenoku, Osaka, Japan 